\title{
Two-Year Clinical Outcome after Carvedilol-Loaded Stent Implantation in Patients with Coronary Artery Disease
}

Hyun Kuk Kim', Young Joon Hong', Myung Ho Jeong', Weon Kim², Sung Soo Kim', Jum Suk Ko', Min Goo Lee', Doo Sun Sim', Keun Ho Park', Nam Sik Yoon', Hyun Ju Yoon', Kye Hun Kim', Hyung Wook Park', Ju Han Kim', Youngkeun Ahn', Jeong Gwan Cho', Jong Chun Park', and Jung Chaee Kang'

1Department of Internal Medicine, The Heart Center of Chonnam National University Hospital, Gwangju; ${ }^{2}$ Cardiovascular Division, Department of Internal Medicine, Kyung Hee University Medical Hospital, Seoul, Korea

Background/Aims: Carvedilol is an antioxidant that inhibits smooth muscle cell proliferation and migration. The aim of this study was to investigate the beneficial effects of carvedilol-loaded stents on 2-year clinical outcomes after stent implantation in patients with coronary artery disease.

Methods: We performed a prospective trial with male subjects to compare the safety and effects of carvedilolloaded BiodivYsio ${ }^{\circledR}$ stents implanted into 20 patients with those of bare-metal BiodivYsio ${ }^{\circledR}$ stents implanted into 21 patients for de novo coronary lesions. The primary end point was the degree of neointimal hyperplasia, which was measured by intravascular ultrasound (IVUS) 6 months after the procedure; the secondary end point was major adverse cardiac events (MACE) at 2 years after implantation. All carvedilol and control stents were deployed successfully.

Results: A 2-year follow-up was completed for 19 patients (95\%) in the carvedilol stent group and 20 patients $(95 \%)$ in the control stent group. IVUS showed a trend toward a larger luminal area (6.86 \pm 2.59 vs. $5.47 \pm 1.52$ $\left.\mathrm{mm}^{2}, p=0.267\right)$, smaller neointimal area (1.34 \pm 0.70 vs. $\left.2.40 \pm 1.73 \mathrm{~mm}^{2}, p=0.18\right)$, and reduced net decrease in luminal area $\left(-0.78 \pm 0.97\right.$ vs. $\left.-1.89 \pm 1.78 \mathrm{~mm}^{2}, p=0.106\right)$ in the carvedilol stent group compared with the control stent group, respectively. There were no significant differences in the incidence of MACE (10.5 vs. $30.0 \%$, respectively, $p=0.132$ ) between the groups at 2 years after stent implantation. Stent thrombosis did not occur in either group after 2 years.

Conclusions: The carvedilol-loaded stents tended to inhibit neointimal hyperplasia without the occurrence of cardiac death, myocardial infarction, or stent thrombosis at 2-year follow-up. (Korean J Intern Med 2011;26:4146)

Keywords: Coronary artery disease; Antioxidants; Stents

\section{INTRODUCTION}

The long-term clinical efficacy of intracoronary stenting is mainly limited by restenosis due to neointimal hyper-plasia, which is caused by inflammation in the vessel wall in response to arterial injury after stent implantation, as well as cytokine- and growth factor-induced smooth muscle migration, proliferation, and proteoglycan deposition [1-3].
Carvedilol is a non-selective $\beta$-adrenergic antagonist and vasodilator with antioxidative and free-radical-scavenging properties [4]. It also inhibits vascular smooth muscle cell proliferation, migration, and extracellular matrix synthesis [5-7]. Carvedilol, therefore, is expected to reduce neointimal hyperplasia, and we previously showed that carvedilolloaded stents were effective in the prevention of coronary restenosis in a porcine model [8]. However, no human

Received: August 20, 2009

Revised : December 11, 2009

Accepted: March 23, 2010 
study has been undertaken to prove their efficacy.

We hypothesized that the delivery of carvedilol by a stent can prevent neointimal hyperplasia and improve long-term clinical outcomes in patients with coronary artery disease. In this study, we investigated the beneficial effects of carvedilol-loaded stents based on 2-year clinical outcomes after stent implantation.

\section{METHODS}

\section{Study population}

We performed a prospective trial using male subjects to compare the safety and effects of carvedilol-loaded BiodivYsio $^{\circledR}$ stents (Biocompatibles Ltd., Farnham, UK) which were implanted into 20 patients, with those of baremetal BiodivYsio ${ }^{\circledR}$ stents, which were implanted into 21 patients for de novo coronary lesions between November 2003 and September 2005 at Chonnam National University Hospital. The inclusion criteria were aged between 18 and 80 years, reference diameter between 2.5 and $4.0 \mathrm{~mm}$, lesion length $<25 \mathrm{~mm}$, and critical stenosis ( $>70 \%$ ) on angiography. Patients with graft-vessel stenosis, cardiogenic shock, a left ventricular ejection fraction $<35 \%$, or contraindications for antiplatelet agents were excluded from the study. The study protocol was reviewed and approved in sequence by the Ministry of Health and Welfare and the Ethics Committee of Chonnam National University Hospital. Informed consent was obtained from all patients.

\section{Stent preparation}

Carvedilol (Boehringer, Mannheim, Germany) was loaded onto $3.0 \times 15 \mathrm{~mm}$ BiodivYsio ${ }^{\circledR}$ drug-delivery stents (Biocompatibles Ltd.) at a concentration of $5 \mathrm{mg} / \mathrm{mL}$, which was prepared by dissolving powdered carvedilol in methanol. Each stent was immersed in the drug solution for 5 minutes, then removed from the solution and airdried. The amount of drug loaded onto the stents was measured by high-performance liquid chromatography (HPLC). The stents were kept in individual vials containing HPLC mobile phase solvent (acetonitrile [60\%] and $0.25 \mathrm{~mol} / \mathrm{L}$ ammonium acetate [40\%]) then placed in an ultrasound bath for a 30-minutes extraction. We previously showed that about $50 \%$ of the loaded carvedilol was released after 5 minutes, $77 \%$ after 30 minutes, and 85\% after 60 minutes based on in vitro release kinetics [8].

\section{Study procedure and definition}

All procedures were done according to standard techniques: randomly selected stents were deployed after predilation with a balloon catheter. Additional balloon dilatation was performed in cases of remaining residual stenosis. All patients received aspirin (300 mg at least 12 hours before stent implantation and $100-200 \mathrm{mg} /$ day indefinitely), ticlopidine (500 $\mathrm{mg}$ at least 6 hours before stent implantation and $250 \mathrm{mg} /$ day for two months), or clopidogrel (300 mg at least 6 hours before stent implantation and $75 \mathrm{mg} /$ day for two months). Unfractionated heparin was administered as a 5,000 U bolus, followed by 1,000 $\mathrm{U} /$ hour and an additional 5,00o U just before percutaneous coronary intervention (PCI) to maintain the activated clotting time at 250-300 seconds.

Coronary angiography was performed at baseline. Quantitative measurements of the diameter of the coronary arteries were obtained by a blinded reviewer using a workstation with dedicated software (Phillips $\mathrm{H}_{5} \mathrm{OOO}$ or Allura DCI). From two orthogonal views, the minimal lumen diameter and interpolated reference diameter were calculated as a mean. All intravascular ultrasound (IVUS) studies were performed at the time of the procedure and 6 months after the procedure by a follow-up angiogram. The images were acquired with motorized pullback at a constant speed of $1 \mathrm{~mm} / \mathrm{sec}$ (Galaxy, Boston Scientific, Natick, MA, USA). Using volumetric analysis, we measured the external elastic membrane (EEM) and lumen cross-sectional area (CSA). The plaque plus media (P\&M) CSA was calculated as the EEM CSA minus the lumen CSA, and the plaque burden was calcul-ated as the P\&M CSA divided by the EEM CSA. The lesion was the site with the smallest lumen CSA. In cases where multiple image slices had the same minimum lumen CSA, the image slice with the largest EEM and P\&M was measured.

A successful procedure was defined as a patient-treated vessel with anterograde thrombolysis in myocardial infarction flow-grade III and angiographic residual stenosis $<20 \%$ without the occurrence of any cardiac events. In-stent restenosis was defined as in-stent luminal diameter stenosis > 50\%; stent thrombosis was defined according to academic research consortium criteria [9].

\section{Study endpoints}

The primary end point was the degree of neointimal hyperplasia, which was measured by IVUS at 6 months after the procedure; the secondary end point was major adverse cardiac events (MACE; cardiac death, non-fatal 
Table 1. Baseline clinical characteristics

\begin{tabular}{|c|c|c|c|}
\hline Characteristics & $\begin{array}{l}\text { Carvedilol stent } \\
\qquad(\mathrm{n}=19)\end{array}$ & $\begin{array}{l}\text { Control stent } \\
\qquad(n=20)\end{array}$ & $p$ value \\
\hline Age, yr & $57.2 \pm 10.4$ & $60.2 \pm 8.4$ & 0.328 \\
\hline Female & $4(21.1)$ & $4(20.0)$ & 0.935 \\
\hline \multicolumn{4}{|l|}{ Risk factor } \\
\hline Diabetes mellitus & $3(15.8)$ & $4(20.0)$ & 0.732 \\
\hline Hypertension & $7(36.8)$ & $8(40.0)$ & 0.839 \\
\hline Dyslipidemia & $7(36.8)$ & $4(20.0)$ & 0.243 \\
\hline Current smoker & $9(47.4)$ & $4(20.0)$ & 0.074 \\
\hline Family history & $2(10.5)$ & $1(5.0)$ & 0.517 \\
\hline Clinical presentation & & & 0.488 \\
\hline Stable angina & $2(10.5)$ & $3(15.0)$ & \\
\hline Unstable angina & $13(68.4)$ & $15(75.0)$ & \\
\hline NSTEMI & $2(10.5)$ & $2(10.0)$ & \\
\hline STEMI & $1(5.3)$ & $0(0.0)$ & \\
\hline Previous $\mathrm{PCl}$ & $1(5.3)$ & $2(10.0)$ & 0.579 \\
\hline Previous Ml & $1(5.3)$ & $1(5.0)$ & 0.970 \\
\hline Creatinine clearance, $\mathrm{mL} / \mathrm{min}$ & $81.62 \pm 13.84$ & $82.45 \pm 19.62$ & 0.882 \\
\hline Ejection fraction, \% & $66.9 \pm 6.3$ & $69.0 \pm 6.9$ & 0.342 \\
\hline
\end{tabular}

Values are presented as number (\%) or mean \pm SD.

NSTEMI, non-ST segment elevation myocardial infarction; STEMI, ST-segment elevation myocardial infarction; PCI, percutaneous coronary intervention; MI, myocardial infarction.

myocardial infarction, and percutaneous or surgical target vessel revascularization) at the 2-year clinical follow-up.

\section{Statistical analysis}

SPSS version 15.0 (SPSS Inc., Chicago, IL, USA), was used for all analyses. Continuous variables are presented as the mean value $\pm \mathrm{SD}$; comparisons were conducted by Student's $t$ test, or by a nonparametric Wilcoxon test if the normality assumption was violated. Discrete variables were presented as percentages and relative frequencies; comparisons were conducted by $\chi^{2}$ statistics or Fisher's exact test as appropriate. A $p$ value $<0.05$ was considered statistically significant.

\section{RESULTS}

\section{Baseline and procedural characteristics}

No significant differences were noted in terms of age, sex, risk factors for coronary artery disease, clinical presentation, creatinine clearance level as calculated by the Cockcroft-Gault equation, and left ventricular ejection fraction between the groups (Table 1).

The two groups showed no significant difference in the target vessels, the number of diseased vessels, or ACC/ AHA lesion type. All carvedilol and control stents were deployed successfully. No significant differences in stent length and diameter were found between the groups (Table 2). No significant complications were detected after the procedure in either group.

\section{IVUS results}

No significant differences in the baseline pre- and postPCI IVUS findings were observed between the groups. Follow-up IVUS showed a trend toward a smaller neointimal area and larger luminal area in the carvedilol-loaded stent group compared with the control stent group. Moreover, there was a trend toward a reduced net decrease in intrastent luminal area in the carvedilol-loaded stent group compared with the control stent group (Table 3).

\section{Clinical follow-up results}

A 2-year follow-up was completed for 19 patients (95\%) in the carvedilol-loaded stent group and 20 patients (95\%) in the control stent group. No significant differences in the incidence of total MACE (10.5 vs. 30.0\%, respectively, $p=$ 0.13), cardiac death (o\% in both groups), nonfatal myocardial infarction ( $0 \%$ in both groups), target lesion 
Table 2. Coronary angiographic characteristics

\begin{tabular}{lcc}
\hline Characteristics & $\begin{array}{c}\text { Carvedilol stent } \\
(\mathrm{n}=19)\end{array}$ & $\begin{array}{c}\text { Control stent } \\
(\mathrm{n}=20)\end{array}$ \\
\hline Baseline angiographic finding & & $14(70.0)$ \\
Target vessel & $11(57.9)$ & $3(15.0)$ \\
$\quad$ Left anterior descending artery & $4(21.1)$ & $3(15.0)$ \\
$\quad$ Left circumflex artery & $4(21.1)$ & $17(85.0)$ \\
$\quad$ Right coronary artery & & $3(15.0)$ \\
Diseased vessel number & $15(78.9)$ & $1(5.0)$ \\
$\quad$ One & $4(21.1)$ & $19(95.0)$ \\
$\quad$ Two & & 0.733 \\
ACC/AHA classification & $0(0.0)$ & $3.09 \pm 0.48$ \\
$\quad$ Type A & $17(94.4)$ & $1.39 \pm 0.50$ \\
$\quad$ Type B1 & $1(5.6)$ & 0.622 \\
$\quad$ Type B2 & $3.08 \pm 0.34$ & $9.12 \pm 3.81$ \\
Reference vessel diameter, mm & $1.04 \pm 0.42$ & 0.367 \\
Pre-procedural MLD, mm & $10.7 \pm 3.26$ & $2.85 \pm 0.49$ \\
Lesion length, mm & & 0.116 \\
Post-procedural finding & $2.87 \pm 0.30$ & 0.357 \\
Post-procedural MLD, mm & & 0.906 \\
\hline
\end{tabular}

Values are presented as number (\%) or mean \pm SD.

ACC/AHA, American College of Cardiology/American Heart Association; MLD, minimal lumen diameter.

Table 3. Intravascular ultrasound results

\begin{tabular}{|c|c|c|c|}
\hline & $\begin{array}{l}\text { Carvedilol stent } \\
\qquad(\mathrm{n}=19)\end{array}$ & $\begin{array}{l}\text { Control stent } \\
(n=20)\end{array}$ & $p$ value \\
\hline \multicolumn{4}{|l|}{ Preintervention } \\
\hline Proximal reference EEM CSA, $\mathrm{mm}^{2}$ & $14.8 \pm 2.28$ & $15.9 \pm 5.26$ & 0.542 \\
\hline Lesion site EEM CSA, mm² & $14.7 \pm 3.25$ & $13.8 \pm 3.75$ & 0.616 \\
\hline Lesion site luminal area, $\mathrm{mm}^{2}$ & $4.27 \pm 1.22$ & $5.67 \pm 3.24$ & 0.251 \\
\hline Lesion site plaque + media CSA $\mathrm{mm}^{2}$ & $10.9 \pm 2.83$ & $8.62 \pm 3.36$ & 0.131 \\
\hline Lesion site plaque burden, $\%$ & $70.2 \pm 8.19$ & $58.4 \pm 21.2$ & 0.120 \\
\hline Distal reference EEM CSA, mm² & $11.5 \pm 3.21$ & $19.2 \pm 18.2$ & 0.206 \\
\hline Postintervention stent CSA & $8.30 \pm 2.05$ & $8.21 \pm 1.79$ & 0.922 \\
\hline \multicolumn{4}{|l|}{ Follow-up } \\
\hline Proximal reference EEM CSA, mm² & $14.7 \pm 2.15$ & $15.2 \pm 3.96$ & 0.685 \\
\hline Stent CSA & $8.26 \pm 2.15$ & $7.87 \pm 1.59$ & 0.724 \\
\hline Intrastent luminal area, $\mathrm{mm}^{2}$ & $6.86 \pm 2.59$ & $5.47 \pm 1.52$ & 0.267 \\
\hline Intrastent $\mathrm{NIH}$ area, $\mathrm{mm}^{2}$ & $1.34 \pm 0.70$ & $2.40 \pm 1.73$ & 0.181 \\
\hline Distal reference EEM CSA, mm² & $11.6 \pm 3.37$ & $13.0 \pm 4.51$ & 0.438 \\
\hline \multicolumn{4}{|c|}{ Serial comparison between preintervention and follow-up, $\mathrm{mm}^{2}$} \\
\hline$\Delta$ proximal reference EEM CSA & $-0.17 \pm 0.23$ & $-0.22 \pm 0.19$ & 0.592 \\
\hline$\Delta$ stent CSA & $-0.08 \pm 0.23$ & $-0.02 \pm 0.23$ & 0.598 \\
\hline$\Delta$ intrastent luminal area & $-0.78 \pm 0.97$ & $-1.89 \pm 1.78$ & 0.106 \\
\hline$\Delta$ distal reference EEM CSA & $-0.27 \pm 0.51$ & $-0.53 \pm 0.94$ & 0.453 \\
\hline
\end{tabular}

Values are presented as mean \pm SD.

EEM, external elastic membrane; CSA, cross-sectional area; $\mathrm{NIH}$, neointimal hyperplasia. 
Table 4. Clinical outcomes at 2-year follow-up after stent implantation

\begin{tabular}{llll}
\hline & $\begin{array}{c}\text { Carvedilol stent } \\
(\mathrm{n}=19)\end{array}$ & $\begin{array}{c}\text { Control stent } \\
(\mathrm{n}=20)\end{array}$ & $p$ value \\
\hline $\begin{array}{l}\text { Total MACE } \\
\text { Cardiac death }\end{array}$ & $0(0.0)$ & $0(0.0)$ & 1.00 \\
Nonfatal MI & $0(0.0)$ & $0(0.0)$ & 1.00 \\
TLR & $2(10.5)$ & $5(25.0)$ & 0.239 \\
TVR & $2(10.5)$ & $6(30.0)$ & 0.132 \\
CABG & $0(0.0)$ & $0(0.0)$ & 1.00 \\
\hline
\end{tabular}

Values are presented as number (\%).

MACE, major adverse cardiac events; MI, myocardial infarction; TLR, target lesion revascularization; TVR, target vessel revascularization; CABG, coronary artery bypass graft.

revascularization (10.5 vs. $25.0 \%, p=0.24$ ), and target vessel revascularization (10.5 vs. $30.0 \%, p=0.13$ ) between groups were found. Neither group showed stent thrombosis at the 2-year follow-up (Table 4).

\section{DISCUSSION}

This study is the first randomized, prospective clinical trial to evaluate the effects of carvedilol-loaded stents in patients with coronary artery disease in terms of their long-term clinical outcomes. Patients who received carvedilol-loaded stents were free of procedure-related complications and acute, subacute, late, and very late stent thrombosis.

Although the incidence of MACE was not significantly different between the two groups, the target vessel revascularization rate was almost three times higher in the control bare-metal stent group compared with the carvedilol stent group. Additionally, a tendency toward decreased neointimal hyperplasia in serial IVUS measure-ments was observed in the carvedilol stent group despite a larger plaque burden before stenting. The carvedilol-loaded stents, therefore, were expected to have a potential therapeutic benefit for the prevention of in-stent restenosis.

Recent advances in drug-eluting stents have markedly reduced the incidence of in-stent restenosis [10,11]. However, no improvement in terms of long-term prognosis [12] has occurred, possibly due to late or very late stent thrombosis [13]. Re-endothelialization and the inhibition of wound healing by paclitaxel and sirolimus have been suggested as a biologic mechanism of late stent thrombosis [14,15]. At the 2-year follow-up, late or very late stent thrombosis was absent in the carvedilol-loaded stent group. In our previous porcine study [8], pathologic examination at $\mathbf{2 8}$ days after stent implantation revealed complete and equivalent healing and re-endothelialization in the control, probucol, and carvedilol-loaded stent groups. In addition, pharmacological studies have revealed that carvedilol may protect the ischemic myocardium and offer vascular protection against other chronic pathological processes, including atherosclerosis and acute vascular injuries arising from coronary artery procedures due to its antioxidative and anti-inflammatory properties [16]. Nevertheless, it is unknown whether carvedilol itself promotes re-endothelialization, similar to probucol [17].

The main limitations of this study are the small number of patients and the fact that it was a single-center study. Specifically, our study included only 41 patients with de novo, single-vessel, relatively simple lesions. Considering the small number of patients used to assess the clinical outcomes, a large-population study is needed to evaluate the safety and efficacy of carvedilol-loaded stents.

In conclusion, the carvedilol-loaded stents used in this study tended to inhibit neointimal hyperplasia without the occurrence of cardiac death, myocardial infarction, and stent thrombosis. These observations require confirmation in a large, randomized, multicenter study.

\section{Conflict of interest}

No potential conflict of interest relevant to this article was reported. 


\section{Acknowledgements}

This study was supported by a grant from the Korean Healthcare Technology R\&D Project, Ministry for Health, Welfare and Family Affairs, Republic of Korea (Ao84869).

\section{REFERENCES}

1. Grewe PH, Deneke T, Machraoui A, Barmeyer J, Müller KM. Acute and chronic tissue response to coronary stent implantation: pathologic findings in human specimen. J Am Coll Cardiol 2000;35:157-163.

2. Farb A, Sangiorgi G, Carter AJ, et al. Pathology of acute and chronic coronary stenting in humans. Circulation 1999;99:44-52.

3. Kornowski R, Hong MK, Tio FO, Bramwell O, Wu H, Leon MB. In-stent restenosis: contributions of inflammatory responses and arterial injury to neointimal hyperplasia. J Am Coll Cardiol 1998;31:224-230.

4. Yue TL, Cheng HY, Lysko PG, et al. Carvedilol, a new vasodilator and beta adrenoceptor antagonist, is an antioxidant and free radical scavenger. J Pharmacol Exp Ther 1992;263:92-98.

5. Ohlstein EH, Douglas SA, Sung CP, et al. Carvedilol, a cardiovascular drug, prevents vascular smooth muscle cell proliferation, migration, and neointimal formation following vascular injury. Proc Natl Acad Sci U S A 1993;90:6189-6193.

6. Sung CP, Arleth AJ, Ohlstein EH. Carvedilol inhibits vascular smooth muscle cell proliferation. J Cardiovasc Pharmacol 1993;21:221-227.

7. Park J, Ha H, Kim MS, Ahn HJ, Huh KH, Kim YS. Carvedilol inhibits platelet-derived growth factor-induced extracellular matrix synthesis by inhibiting cellular reactive oxygen species and mitogen-activated protein kinase activation. J Heart Lung Transplant 2006;25:683-689.

8. Kim W, Jeong MH, Cha KS, et al. Effect of anti-oxidant (carvedilol and probucol) loaded stents in a porcine coronary restenosis model. Circ J 2005;69:101-106.

9. Cutlip DE, Windecker S, Mehran R, et al. Clinical end points in coronary stent trials: a case for standardized definitions. Circulation 2007;115:2344-2351.

10. Park SJ, Shim WH, Ho DS, et al. A paclitaxel-eluting stent for the prevention of coronary restenosis. N Engl J Med 2003;348:15371545 .

11. Moses JW, Leon MB, Popma JJ, et al. Sirolimus-eluting stents versus standard stents in patients with stenosis in a native coronary artery. N Engl J Med 2003;349:1315-1323.

12. Spaulding C, Daemen J, Boersma E, Cutlip DE, Serruys PW. A pooled analysis of data comparing sirolimus-eluting stents with bare-metal stents. N Engl J Med 2007;356:989-997.

13. Bavry AA, Kumbhani DJ, Helton TJ, Borek PP, Mood GR, Bhatt DL. Late thrombosis of drug-eluting stents: a meta-analysis of randomized clinical trials. Am J Med 2006;119:1056-1061.

14. Inoue T, Node K. Molecular basis of restenosis and novel issues of drug-eluting stents. Circ J 2009;73:615-621.

15. Luscher TF, Steffel J, Eberli FR, et al. Drug-eluting stent and coronary thrombosis: biological mechanisms and clinical implications. Circulation 2007;115:1051-1058.

16. Feuerstein GZ, Ruffolo RR Jr. Carvedilol, a novel vasodilating beta-blocker with the potential for cardiovascular organ protection. Eur Heart J 1996;17 Suppl B:24-29.

17. Tanous D, Brasen JH, Choy K, et al. Probucol inhibits in-stent thrombosis and neointimal hyperplasia by promoting re-endothelialization. Atherosclerosis 2006;189:342-349. 